\title{
IKLAN PENYEDIA JASA KLENIK DI SITUS INTERNET BELANDA: ANALISIS TINDAK TUTUR
}

\author{
Eda Amelinda ${ }^{1}$, Munif Yusuf ${ }^{2}$ \\ ${ }^{12}$ Fakultas Ilmu Pengetahuan Budaya, Universitas Indonesia \\ Pos-el: eda.amelinda@ui.ac.id ${ }^{1}$, munifyusuf@yahoo.co.id ${ }^{2}$
}

\begin{abstract}
Abstrak
Masyarakat Belanda biasanya tidak percaya pada hal-hal yang tidak masuk akal, tetapi terdapat juga orang-orang yang mempercayai hal-hal berbau klenik. Para penyedia jasa klenik mengiklankan produknya menggunakan iklan melalui situs internet. Penelitian ini membahas tindak tutur dan penggunaan nama diri pada iklan penyedia jasa klenik di situs internet Belanda. Penelitian dilakukan dengan menganalisis tindak tutur menggunakan teori tindak tutur Searle (1977), menentukan jenis tindak tutur, serta mengkaji penggunaan nama diri yang digunakan oleh penyedia jasa klenik menggunakan pendapat David Crystal (1987). Hasil penelitian ini menunjukkan tindak tutur yang banyak digunakan oleh penyedia jasa klenik adalah tindak tutur komisif dan tindak tutur direktif. Selain itu ditemukan penggunaan nama diri yang diikuti kata sapaan dalam bahasa Inggris atau Belanda dan penggunaan nama diri yang diikuti gelar. Kata Kunci: Iklan klenik; masyarakat Belanda; nama diri; tindak tutur komisif; tindak tutur direktif.
\end{abstract}

\begin{abstract}
The Dutch usually does not believe in things that do not make sense, but there are also people who believe in mystical things. The mystical services advertise their service using advertisements through internet sites. This research discusses speech acts and the use of proper name in advertisements of the mystical services on Dutch internet sites. The research analyzed speech act using Searle's concept (1977), determined the type of speech act, and observed the use of proper name using Crystal's opinion (1987). The result of this research shows that the type of speech act that are commonly used by the mystical services are commissive speech act and directive speech act. As well as the use of proper name followed by addressing term in both English and Dutch also the use of proper name followed by title.
\end{abstract}

Keywords: Mystical advertisement; the Dutch; proper name; commissive speech act; directive speech act. 


\section{PENDAHULUAN}

Belanda merupakan salah satu negara maju yang terdapat di benua Eropa. Salah satu ciri negara maju adalah perkembangan ilmu pengetahuan dan edukasinya dapat dikatakan cukup pesat (Gani et al., 2018). Hal tersebut menyebabkan masyarakatnya memiliki pola pikir yang maju sehingga tidak percaya dengan hal-hal mistis. Dengan pola pikir yang maju, mereka akan lebih cermat dalam bertindak. Salah satu contohnya dalam mengatasi permasalahan hidup yang terlalu berat, mereka akan meminta pertolongan kepada orang yang ahli dalam bidangnya, seperti dokter atau psikolog. Akan tetapi terdapat pula orang Belanda yang percaya pada hal-hal yang berbau klenik. Definisi klenik menurut Kamus Besar Bahasa Indonesia (KBBI) adalah kegiatan perdukunan (pengobatan dan sebagainya) dengan cara-cara yang sangat rahasia dan tidak masuk akal, tetapi dipercayai oleh banyak orang.

Di Belanda terdapat penyedia jasa klenik yang menawarkan jasa untuk membantu orang-orang dalam mengatasi masalah hidupnya. Para penyedia jasa klenik beriklan tentang kemampuan dan kesaktian yang mereka miliki disertai dengan nama diri yang diikuti gelar atau sebutan untuk meyakinkan konsumen. Beberapa contoh di antaranya adalah Paragnost Elisa-Lis, Medium Roos, Mr. Naala, dan Prof. Samiou.

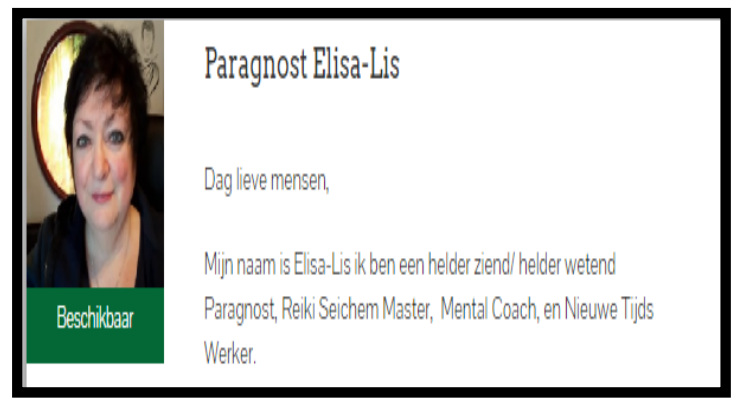

Gambar 1. Iklan Penyedia Jasa Klenik oleh Paragnost ElisaLis

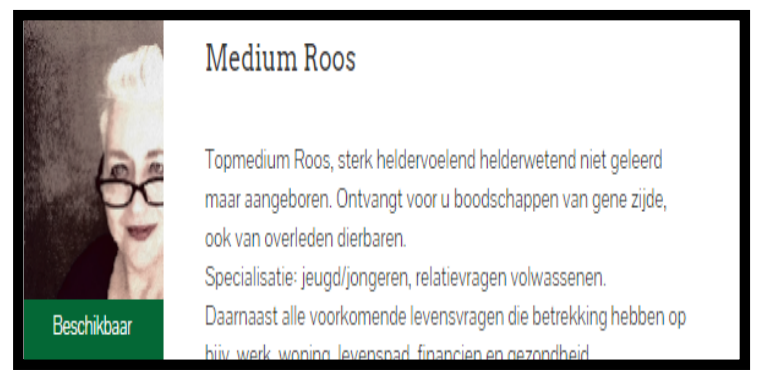

Gambar 2. Iklan Penyedia Jasa Klenik oleh Medium Roos

\section{解 Mr. NAALA}

Helpt om Uw problemen op te lossen.

Gespecialiseerd in: relatie problemen, familie. Bescherming tegen slechte invloeden, geluk in zaken, impotentie, succes verzekerd, onmiddellijke terugkeer van iemand die $U$ verlaten heeft, helpt $U$ ook met hereniging. Ook lichamelijke ziekten.

Als er nog een beetje hoop is of zelfs geen, doe dan als elke andere.

WERKT SERIEUS, SNEL EN GEHEIM. Betaling na resultaat

LAAT UW KANS NIET VOORBIJGAAN. BEL SNEL:

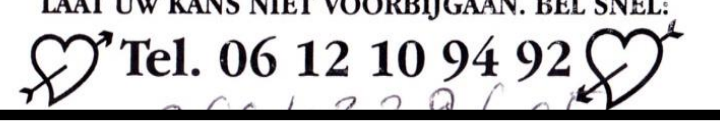

Gambar 3. Iklan Penyedia Jasa Klenik oleh Mr. Naala

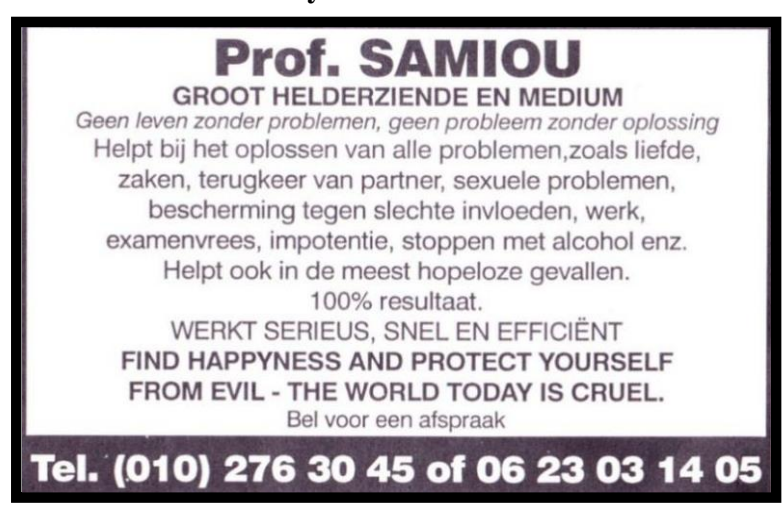

Gambar 4. Iklan Penyedia Jasa Klenik oleh Prof. Samiou 
Para penyedia jasa klenik memiliki harapan agar dirinya dapat diandalkan oleh orang-orang yang tidak tahan dalam menghadapi masalah hidup atau tidak memiliki kepercayaan diri untuk melihat berbagai realitas kehidupan. Penyedia jasa klenik biasanya memasarkan produknya melalui internet. Iklan yang mereka sajikan dikemas sebaik mungkin dengan menggunakan strategi kebahasaan untuk menarik konsumen.

Pada dasarnya, iklan merupakan sebuah media yang memiliki fungsi untuk memberikan informasi mengenai suatu produk atau jasa kepada masyarakat dan menarik perhatian target sasaran untuk menggunakan produk atau jasa yang ditawarkan. Bahasa iklan dikemas semenarik mungkin agar pembacanya dapat terpengaruh. Menurut Danesi dan Perron (1999) iklan merupakan sejenis teks, lebih tepatnya yaitu teks sosial yang memiliki tujuan untuk membujuk, mempengaruhi persepsi untuk membeli dan mengkonsumsi barang, sekaligus memasarkan cara hidup dan membentuk cara pandang. Salah satu contoh kalimat membujuk pada iklan yaitu "The big medium is in the city for all kinds of problems (relationship, better chance, business, etc...). I will help you! Come to see me!" 'Perantara besar di kota untuk segala jenis masalah (hubungan, peluang lebih baik, bisnis, dll). Saya akan membantumu! Temui saya!'

Cara yang digunakan oleh pengiklan untuk menjual produknya beragam, mulai dari menceritakan pengalamannya, memberikan testimoni dari orang-orang yang sudah memakai produknya, dan menggunakan kata-kata yang mengandung majas hiperbola. Iklan yang dimunculkan di berbagai media memiliki tujuan yang sama, yaitu menarik hati serta menciptakan kepercayaan terhadap produk (barang atau jasa) yang diiklankan.

Dalam mengiklankan jasanya, para penyedia jasa klenik menggunakan iklan panjang dan iklan pendek. Iklan panjang yang disajikan tergolong dalam iklan advertorial, iklan yang ditulis dengan menggunakan gaya pemberitaan atau penulisan jurnalisik (Sopian, 2016). Isi pesan yang terdapat dalam iklan advertorial berupa fakta yang diklasifikasi menjadi pengetahuan dan pengalaman serta ditambah pula dengan opini yang dapat mempengaruhi calon konsumen (Martutik, 2013). Berbeda dengan iklan panjang, iklan pendek tergolong dalam iklan kolom. Iklan kolom berisi pesan verbal tertulis dan pesan nonverbal sebagai ilustrasi, misalnya: gambar, simbol, 
lambang, maupun tanda-tanda visual lainnya yang tidak terlalu bervariasi dan terbatas (Veriyani, 2011).

Setelah mengamati berbagai tulisan sampai saat ini belum ditemukan penelitian yang meneliti iklan penyedia jasa klenik di situs internet Belanda dengan menggunakan pendekatan pragmatik. Secara khusus penelitian ini mencermati tindak tutur serta penggunaan nama diri yang terdapat dalam iklan penyedia jasa klenik pada situs internet Belanda. Hal ini yang menjadikan penelitian ini layak untuk dilakukan.

Dilihat dari status negara Belanda yang sudah masuk ke dalam kategori negara maju, hal-hal berbau klenik dapat dikatakan sebagai sesuatu hal yang unik. Para penyedia jasa klenik Belanda mengiklankan jasanya dengan cara yang berbeda-beda. Tujuan penelitian ini adalah untuk memaparkan tindak tutur yang disajikan dalam slogan dan memperlihatkan penggunaan nama diri oleh penyedia jasa klenik Belanda dalam iklannya di situs internet.

Kerangka teoretis berikut mencakup iklan, tindak tutur, dan nama diri. Secara sederhana, Renald Kasali (1995:5) mengatakan bahwa iklan merupakan pesan yang menawarkan suatu produk yang ditunjukkan kepada masyarakat melalui suatu media. Iklan adalah sebuah sarana yang digunakan untuk menawarkan barang dan jasa kepada masyarakat. Informasi yang disampaikan dalam sebuah iklan menggunakan bahasa yang mudah dipahami oleh konsumen dan lebih banyak menggunakan kata-kata persuasif yang bertujuan agar konsumen tertarik untuk membeli atau mencobanya. Secara pragmatik, pesan sebuah iklan berguna untuk mempengaruhi orang lain agar melakukan transaksi komoditas. Secara semantik, iklan merupakan pesan mengenai produk, ketersediaannya, dan ajakan pembeliannya (Nöth, 1990).

Teori tindak tutur yang digunakan untuk penelitian ini adalah teori tindak tutur yang dikembangkan oleh John R. Searle (1977). Seperti yang dikutip dari Kumalasari (2015), Searle mengungkapkan bahwa kesatuan dasar dari sebuah komunikasi tidak hanya sekadar kumpulan simbol, kata atau kalimat saja, melainkan lebih ke hasil dari itu semua yang diwujudkan sebagai perilaku tindak tutur. Searle dalam Rohmadi (2004:30) juga mengatakan bahwa kalimat yang dikatakan oleh penutur mampu mengandung tiga tindak tutur sekaligus, yaitu tindak tutur lokusi, tindak tutur ilokusi serta tindak tutur perlokusi. 
Iklan Penyedia Jasa Klenik di Situs Internet...

Tindak tutur yang pertama yaitu tindak tutur lokusi. Houtkoop dan Koole (2000:2) mengatakan bahwa tindak tutur lokusi merupakan tindakan dalam mengatakan sesuatu, penutur menggabungkan kata dengan makna yang sebenarnya. Pada tindak tutur lokusi tidak terdapat maksud tersirat, karena hal yang diutamakan adalah ujaran dengan maksud yang jelas dari penutur. Tindak tutur berikutnya yaitu tindak tutur ilokusi. Menurut Houtkoop dan Koole (2002:2) dengan mewujudkan tindak tutur ilokusi maka penutur menyampaikan maksud tertentu dalam kalimat yang diucapkannya. Maksud yang terdapat dalam ujaran tersebut disebut juga implikatur (Kushartanti, 2005). Contoh tindak tutur ilokusi dapat dilihat pada kalimat "Kun je het raam even dicht doen?" 'Bisakah kamu menutup jendela tersebut?' (Baker et al., 2013). Implikatur dari kalimat tersebut adalah penutur berharap mitra tutur mampu menutup jendela tersebut, ia tidak mengharapkan jawaban "ya" atau "tidak" (Baker et al., 2013). Berdasarkan tujuannya tindak tutur ilokusi dapat dikelompokkan menjadi berikut (Kushartanti, 2005).

1) Tindak tutur asertif adalah tindak tutur ilokusi yang mengharuskan penutur pada kebenaran dan kecocokan proposisi yang dikatakan. Tindak tutur yang bermaksud untuk menyatakan, menyarankan, melaporkan, menyimpulkan sesuatu dapat masuk ke dalam jenis tindak tutur ini. Contoh kalimat yang diberikan Houtkoop dan Koole (2000:29) yaitu "Het regent $n u$ " 'Sekarang hujan'. Implikatur yang berada pada kalimat tersebut adalah penutur ingin melaporkan cuaca yang sedang terjadi pada saat itu.

2) Tindak tutur direktif adalah tindak tutur ilokusi yang bertujuan agar mitra tutur melakukan perbuatan yang dimaksudkan dalam tuturan tersebut. Tindak tutur yang dapat masuk ke dalam jenis tindak tutur direktif yaitu meminta, menyuruh, memohon, memerintahkan, mengajak, dan mengingatkan. Contoh kalimat yang diberikan Houtkoop dan Koole (2000:33) adalah "Op zondag geef ik een feestje, dan zou ik leuk vinden als jij ook kwam" 'Pada hari minggu aku mengadakan sebuah pesta, aku akan senang jika kamu juga datang'. Implikatur yang terdapat pada contoh kalimat tersebut yaitu penutur meminta atau mengundang mitra tutur untuk datang ke pesta yang ia adakan.

3) Tindak tutur komisif adalah tindak tutur ilokusi yang membuat penutur terlibat dengan tindakan atau dampak selanjutnya. Tindak tutur bertujuan untuk bersumpah, 
berjanji, menjamin, dan mengancam termasuk dalam tindak tutur komisif. Contoh kalimat yang diberikan Houtkoop dan Koole (2000:20) yaitu "Morgen ga ik komen" 'Besok aku akan datang'. Implikatur yang ada pada kalimat tersebut adalah penutur berjanji kepada mitra tutur bahwa besok ia akan datang.

4) Tindak tutur ekspresif adalah tindak tutur ilokusi yang memiliki maksud untuk memperlihatkan sikap psikologis penutur pada keadaan tertentu. Tindak tutur yang dapat masuk ke dalam jenis tindak tutur ini adalah tindak tutur yang memiliki tujuan untuk berterima kasih, mengucapkan selamat, berduka, memuji, meminta maaf, memaafkan. Contoh kalimat yang diberikan Houtkoop dan Koole (2000: 29) adalah "Het spijt me dat je gezakt bent" "Saya turut sedih atas kegagalanmu'. Implikatur yang terdapat pada kalimat tersebut adalah penutur bermaksud untuk mengungkapkan kesedihannya atas kegagalan yang dialami oleh mitra tuturnya. Selain itu penutur juga ingin menguatkan mitra tuturnya.

5) Tindak tutur deklaratif adalah tindak tutur ilokusi yang memperlihatkan suatu perubahan status atau keadaan setelah dikatakan. Tindak tutur yang bertujuan untuk menikahkan, menceraikan, membaptis dapat masuk ke dalam jenis tindak tutur deklaratif. Menurut Austin dalam Khoirunnisa (2018), terdapat banyak kalimat deklaratif yang tidak mendeskripsikan atau menyatakan apapun, sehingga tidak dapat dinyatakan benar-salahnya. Ujaran dari kalimat tersebut merupakan bagian dari kegiatan atau tindakan. Contohnya pada kalimat "Saya nikahkan...dengan mas kawin seperangkat alat salat dibayar tunai” yang diucapkan oleh penghulu di acara pernikahan. Kalimat tersebut merupakan tindakan penghulu dalam menikahkan pasangan pengantin, bukan sekadar perkataan saja. Contoh kalimat tindak tutur deklaratif yang diberikan oleh Houtkoop dan Koole (2000:30) yaitu "Hierbij doop ik U Johanna Maria" 'Dengan ini saya baptis Anda Johanna Maria'. Implikatur yang ada pada kalimat tersebut yaitu penutur bermaksud untuk melakukan tindakan membaptis mitra tuturnya sesuai dengan aturan yang berlaku. Tindak tutur yang terakhir yaitu tindak tutur perlokusi. Menurut Kushartanti (2005:109) tindak tutur perlokusi merupakan efek yang timbul akibat dari kalimat yang diutarakan oleh penutur.

Di dalam sebuah iklan, setiap unsurunsurnya harus saling berkesinambungan 
agar memudahkan objek sasaran pasar untuk memahami pesan yang ingin disampaikan dalam iklan tersebut. Pemilihan kata yang digunakan pada masing-masing unsur harus diperhatikan. Pemilihan kata yang diterapkan dalam iklan diutamakan singkat, padat, dan jelas sehingga pembaca akan langsung paham dengan pesan yang disampaikan.

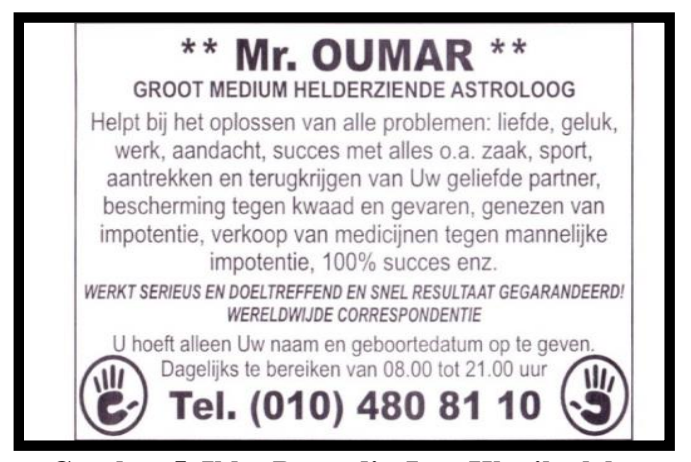

Gambar 5. IklanPenyedia Jasa Klenik oleh Mr. Oumar

Contohnya dalam iklan penyedia jasa klenik di atas, pemilihan kata yang digunakan pada nama diri dan isi iklan harus berhubungan dengan klenik. Seperti yang dapat dilihat pada iklan di atas, hal yang terlintas dipikiran calon konsumen saat melihat penggunaan nama diri "Mr. Oumar" dan kalimat "GROOT MEDIUM HELDERZIENDE ASTROLOOG"

'Perantara peramal astrolog unggul' yaitu ia mengetahui bahwa iklan tersebut merupakan iklan penyedia jasa klenik, serta penggunaan kata $M r$. untuk melengkapi nama diri membuat calon konsumen memberi persepsi yang lebih baik karena kata tersebut merupakan bahasa asing. Kata-kata di dalam sebuah iklan biasanya mengandung majas hiperbola. Majas hiperbola adalah gaya bahasa yang menyatakan sesuatu secara berlebihan (Handayani, 2018). Seperti yang dikutip dari Handayani (2018), Zaimar (2002) berpendapat bahwa hiperbola merupakan ucapan (ungkapan, pernyataan) kiasan yang dibesar-besarkan, dimaksudkan untuk memperoleh efek tertentu, bukan yang sebenarnya.

Secara kebahasaan, kajian nama merupakan kajian linguistik yang memfokuskan kepada kajian nama orang dan kajian nama tempat (Pramita et al., 2017). Crystal dalam Pramita (2017) mengatakan sebutan untuk ilmu studi nama-nama disebut sebagai onomastics. Menurut Crystal, onomastics dapat memanfaatkan sudut pandang dari bidang keilmuan yang berbeda-beda untuk menelusuri objek studinya, contohnya seperti bidang linguistik, filsafat, sosiologi, dan antropologi (Indrawan, 2015). Seperti yang dikutip dari Indrawan (2015), Mulyana (2005) mengatakan bahwa nama diri mempengaruhi cara masyarakat memberikan persepsinya terhadap si pemilik nama diri, pengharapan masyarakat terhadap orang tersebut, dan 
cara masyarakat memperlakukan orang tersebut.

\section{METODE PENELITIAN}

Langkah pertama yang dilakukan untuk penelitian ini adalah mencari iklan penyedia jasa klenik yang beredar di mesin pencari google.nl dengan memasukkan kata kunci helderziend advertentie dan paragnost advertentie, kemudian pencarian dilakukan melalui google gambar. Pada google gambar ditemukan situs yang menampilkan iklan pendek penyedia jasa klenik. Situs yang memuat $\underline{\text { iklan }}$ pendek penyedia jasa

klenikadalahhttp://www.rahrp.org/cms/vis uals/flyers-on-healing-and-

problemsolving/. Pada situs tersebut terdapat 257 iklan pendek penyedia jasa klenik. Adanya kemiripan slogan pada tiap iklan di situs tersebut menyebabkan iklan yang diambil untuk diteliti hanya 4 buah iklan.

Langkah kedua yaitu mengamati iklan yang sudah didapat. Dari banyaknya iklan penyedia jasa klenik yang ditemukan pada situs http://www.rahrp.org/cms/visuals/flyerson-healing-and-problemsolving/ dapat disimpulkan penyedia jasa klenik pada situs tersebut diduga bukan orang Belanda asli (allochtonen). Kesimpulan tersebut dilihat dari para penyedia jasa klenik yang diduga allochtonen menggunakan nama yang tidak lazim di kebiasaan penamaan orang Belanda. Penelitian ini hanya akan memfokuskan pada iklan penyedia jasa klenik yang diduga allochtonen pada situs http://www.rahrp.org/cms/visuals/flyerson-healing-and-problemsolving/. Alasan dipilihnya iklan penyedia jasa klenik yang diduga allochtonen karena adanya keunikan dari cara penyajian yang digunakan oleh penyedia jasa klenik tersebut dalam mengiklankan jasanya.

Langkah ketiga adalah mengamati data-data yang telah dipilih, kemudian mencatat data iklan seperti tindak tutur dan penggunaan nama diri dari iklan tersebut. Langkah terakhir yaitu menganalisis tindak tutur dengan cara melihat slogan yang terdapat dalam iklan tersebut. Terdapat berbagai cara yang digunakan oleh penyedia jasa klenik untuk menekankan slogan tersebut, di antaranya yaitu penggunaan kalimat dengan bahasa Inggris, tulisan yang diketik dengan huruf kapital, cetak tebal dan cetak miring. Setelah menentukan slogan maka penulis akan melihat jenis tindak tutur yang terdapat pada kalimat tersebut. Berikutnya penulis akan menganalisis penggunaan nama diri dan kalimat yang menjadi ciri dari si penyedia jasa klenik dengan menggunakan landasan teori. 


\section{HASIL DAN PEMBAHASAN}

Dalam keempat iklan pendek penyedia jasa klenik yang telah dipilih dari situs http://www.rahrp.org/cms/visuals/flyerson-healing-and-problemsolving/

ditemukan kalimat slogan dalam bahasa Belanda maupun bahasa Inggris serta penggunaan nama diri diikuti dengan kata sapaan maupun gelar. Definisi slogan menurut Kamus Besar Bahasa Indonesia (KBBI) yaitu perkataan atau kalimat pendek yang menarik atau mencolok dan mudah diingat untuk memberitahukan sesuatu. Slogan mempunyai ciri-ciri yang membedakannya dengan ungkapan yang lain, yaitu hanya terdiri dari beberapa kata dan menarik karena memiliki tujuan utama agar mudah diingat, menjelaskan tentang sesuatu (suatu produk atau layanan masyarakat), dan slogan dapat berupa semboyan sebuah organisasi atau masyarakat (Rahayu et al., 2018). Pada bagian pembahasan ini akan dijelaskan jenis tindak tutur yang terdapat pada kalimat slogan dalam iklan penyedia jasa klenik. Penjelasan mengenai penggunaan nama diri dan kalimat yang menjadi ciri identitas diri juga akan dijelaskan dalam bagian ini.

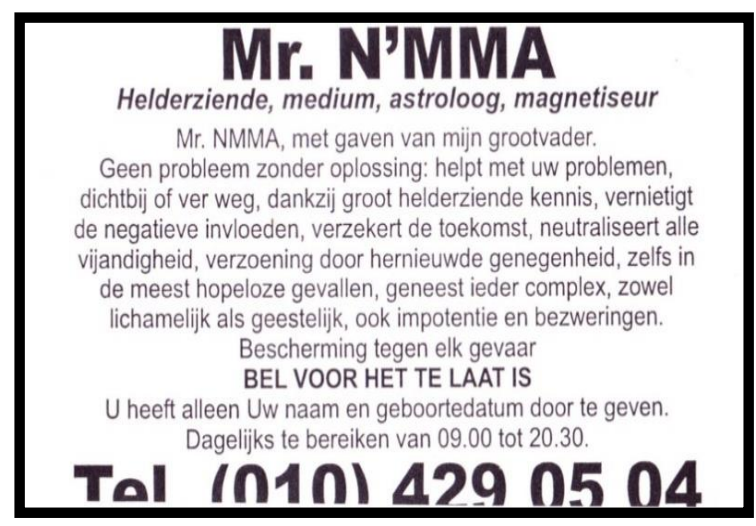

Gambar 6. Iklan Penyedia Jasa Klenik oleh Mr. N'mma

Pada iklan penyedia jasa klenik di atas terdapat sebuah slogan yang berbunyi "BEL VOOR HET TE LAAT IS" 'Telefon sebelum terlambat'. Bentuk tindak tutur lokusi yang terdapat pada kalimat slogan tersebut adalah sebuah pernyataan. Penyedia jasa klenik tersebut memberitahu calon konsumennya untuk menghubungi dirinya sebelum terlambat. Implikatur yang ingin disampaikan penyedia jasa klenik adalah memperingatkan mitra tutur agar segera menghubunginya untuk menggunakan jasa yang ditawarkan sebelum masalah yang dimiliki oleh mitra tutur semakin parah. Tidak hanya memperingatkan, melalui kalimat "VOOR HET TE LAAT $I S$ ' 'Sebelum terlambat' penyedia jasa klenik juga bermaksud untuk menakutnakuti mitra tuturnya. Apabila mitra tuturnya tidak segera menghubungi penutur maka masalah yang ia miliki tidak akan ada solusinya dan malah 
menjadi semakin parah. Jadi berdasarkan tujuannya, dapat dikatakan bahwa kalimat slogan tersebut masuk ke dalam tindak tutur direktif karena mengingatkan mitra tuturnya dan tindak tutur komisif karena menakut-nakuti mitra tuturnya.

Pada iklan di atas dapat dilihat bahwa penyedia jasa klenik yang bernama N'MMA menggunakan nama diri berupa Mr. N'MMA. Kata $M r$. sendiri adalah kependekan dari Mister yang merupakan kata sapaan dalam bahasa Inggris. Penyedia jasa klenik tersebut berada di Belanda tetapi ia memilih untuk menggunakan kata sapaan dalam bahasa Inggris, bukan dalam bahasa Belanda yang berupa Meneer/Mijnheer/Meester. Alasan pemilihan kata sapaan tersebut karena kata $M r$. dianggap lebih menjual dan memiliki prestise (Manurung, 2009). Melalui kata sapaan $M r$. calon konsumen akan menganggap bahwa penyedia jasa klenik tersebut merupakan orang yang berkelas. Pada iklan di atas terlihat terdapat kalimat "Helderziende, medium, astroloog, magnetiseur" 'Peramal, perantara, astrolog, magnetiseur' tepat di bawah nama Mr. N'MMA. Fungsi dari kalimat tersebut adalah untuk menjelaskan identitas diri Mr. N'MMA yang memiliki profesi sebagai seorang peramal, perantara, astrolog, dan magnetiseur ${ }^{1}$.

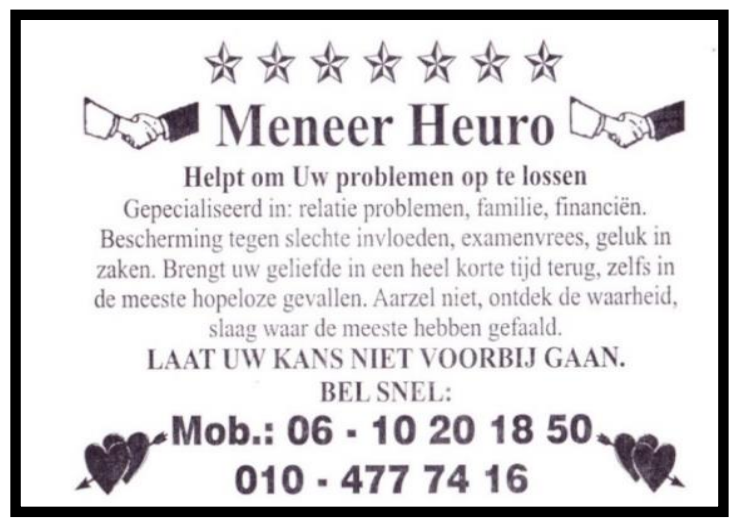

Gambar 7. Iklan Penyedia Jasa Klenik oleh Meneer Heuro

Slogan yang digunakan oleh penyedia jasa klenik di atas yaitu " $L A A T$ UW KANS NIET VOORBIJ GAAN. BEL SNEL" 'Jangan lewatkan kesempatan Anda. Segera hubungi'. Slogan tersebut memiliki tindak tutur lokusi yang sama dengan ilokusinya karena kalimat yang disajikan dalam slogan mengandung makna tersurat. Kalimat "LAAT UW KANS NIET VOORBIJ GAAN." 'Jangan lewatkan kesempatan Anda.' berisi implikatur dari penyedia jasa klenik yang ingin memperingatkan kepada mitra tuturnya agar jangan sampai melewatkan kesempatan untuk menemukan jalan keluar dari masalah yang dihadapi melalui jasa yang ditawarkan oleh penyedia jasa klenik. Pada kalimat "BEL SNEL"

\footnotetext{
${ }^{1}$ Menurut vandale.nl magnetiseur adalah "genezer die door handoplegging mensen van hun kwalen probeert te verlossen" "seseorang yang menyembuhkan orang dengan menempatkan tangannya di badan orang tersebut'
} 
Iklan Penyedia Jasa Klenik di Situs Internet...

'Segera telepon', implikatur dari penyedia jasa klenik yaitu memerintahkan calon konsumen untuk segara menghubunginya untuk mendapatkan bantuan apabila memiliki masalah seperti yang telah ia sebutkan pada kalimat sebelumnya. Berdasarkan pada uraian di atas, implikatur dari kedua kalimat tersebut adalah memperingatkan dan memerintahkan calon konsumen. Kedua kalimat tersebut dapat digolongkan ke dalam tindak tutur direktif.

Penyedia jasa klenik pada iklan di atas memilih menggunakan nama diri berupa Meneer Heuro. Kata Meneer merupakan kata sapaan dalam bahasa Belanda yang berarti tuan. Menurut Quasthoff (1978) dalam Bustarini (1992) penggunaan kata sapaan secara tidak langsung dapat mencerminkan hubungan di antara penuturnya, seperti penghormatan. Penggunaan kata sapaan dalam bahasa Belanda dilakukan karena penyedia jasa klenik yang diduga merupakan bukan orang Belanda asli ingin mendapat penghormatan dari calon konsumennya yang merupakan orang Belanda. Melalui kata sapaan Meneer ia berharap calon konsumennya akan memberi perlakuan yang sama seperti ke orang Belanda asli lainnya. Kalimat yang diletakkan Meneer Heuro di bawah namanya, "Helpt om Uw problemen op te lossen" 'Membantu untuk menyelesaikan masalah Anda' berfungsi untuk memberikan informasi kepada calon konsumen bahwa ia akan membantu calon konsumennya untuk menyelesaikan masalah yang ia hadapi.

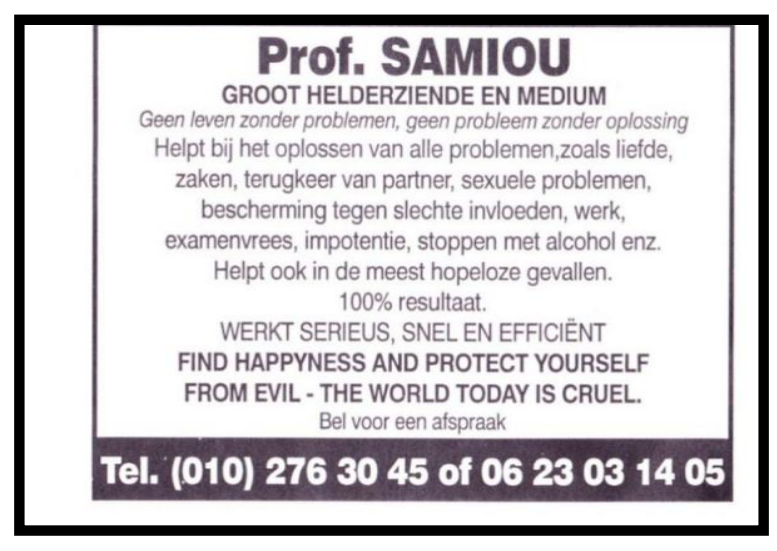

Gambar 8. Iklan Penyedia Jasa Klenik Prof. Samiou

Kalimat slogan pada iklan di atas "WERKT SERIEUS, SNEL EN EFFICIËNT' 'Bekerja serius, cepat, dan efisien' memiliki tindak tutur lokusi berupa sebuah pernyataan. Penyedia jasa klenik memberitahu calon konsumennya bahwa ia bekerja secara serius, cepat, dan efisien. Maksud tersirat dari penyedia jasa klenik adalah memberikan jaminan kepada calon konsumen bahwa ia bekerja secara serius, cepat, dan efisien. Biasanya ketika orang memiliki masalah pasti membutuhkan penanganan yang cepat dan serius sehingga masalahnya cepat terselesaikan. Fungsi dari kalimat tersebut yaitu guna menarik perhatian calon konsumen agar yakin bahwa masalahnya dapat diselesaikan secara cepat dengan orang yang tepat. 
Eda Amelinda, Munif Yusuf...

Penyedia jasa klenik juga menyampaikan slogan dalam bahasa Inggris yaitu "FIND HAPPYNESS AND PROTECT YOURSELF FROM EVIL - THE WORLD TODAY IS CRUEL" 'Temukan kebahagiaan dan lindungi dirimu dari iblis - Saat ini dunia kejam'. Pada kalimat “FIND HAPPYNESS AND PROTECT YOURSELF FROM EVIL" 'Temukan kebahagiaan dan lindungi dirimu dari iblis', tindak tutur lokusinya adalah sebuah kalimat imperatif. Penyedia jasa klenik memerintahkan calon konsumennya untuk mencari kebahagiaan dan perlindungan diri dari iblis. Maksud tersirat dari kalimat tersebut adalah ia juga memberi jaminan kepada calon konsumennya apabila dirinya dapat memberikan kebahagiaan dan melindungi diri mereka dari iblis. Tindak tutur lokusi pada kalimat "THE WORLD TODAY IS CRUEL" "Saat ini dunia kejam" adalah sebuah pernyataan. Penyedia jasa klenik memberitahu calon konsumennya bahwa dunia saat ini kejam. Implikatur dari kalimat tersebut adalah penyedia jasa klenik mencoba menakut-nakuti calon konsumen. Dunia saat ini dapat dikatakan kejam karena pada kenyataannya sekarang manusia hidup di dunia yang penuh dengan ketidakadilan, kekerasan, kejahatan, kesengsaraan, dan hal-hal kejam lainnya. Penggunaan slogan dengan bahasa Inggris yang digunakan oleh penyedia jasa klenik di atas berfungsi untuk menunjukkan gengsi dari jasa yang ditawarkan. Di sisi lain orang Belanda pada umumnya juga menguasai bahasa Inggris yang merupakan lingua franca. Orang Belanda sudah mulai mempelajari bahasa Inggris sejak kecil. Rata-rata orang Belanda tidak begitu menghargai Bahasa Belanda, karena itu mereka merasa bangga dapat menguasai bahasa Inggris dan lebih sering menggunakan bahasa Inggris jika mereka berbicara dengan orang asing (Alex, 2019). Bahkan dengan orang Belgia pun yang nota bene berbahasa Belanda, mereka pun lebih suka berbahasa Inggris. Alasan lain menggunakan slogan dalam bahasa Inggris karena dapat menunjukkan sisi intelektual si penyedia jasa klenik. Berdasarkan tujuannya, maka ketiga kalimat di atas masuk ke dalam jenis tindak tutur komisif karena penyedia jasa klenik memberikan jaminan dan menakut-nakuti calon konsumennya.

Seperti yang dapat dilihat pada iklan di atas, penyedia jasa klenik yang bernama Samiou menggunakan nama diri berupa Prof. Samiou. Penggunaan nama diri dengan menggunakan gelar berfungsi untuk meyakinkan calon konsumen bahwa penyedia jasa klenik tersebut merupakan orang yang berpendidikan tinggi sehingga jasa yang ditawarkan dan kualitas dirinya 
Iklan Penyedia Jasa Klenik di Situs Internet...

dapat dipercaya. Di bawah nama Prof. Samiou terdapat kalimat yang menandakan ciri dari dirinya yaitu "GROOT HELDERZIENDE EN MEDIUM" 'Peramal dan perantara besar'. Melalui kata “GROOT" 'Besar' tersebut penyedia jasa klenik ingin menunjukkan kehebatan dirinya kepada calon konsumen. Kalimat yang menandakan ciri Prof. Samiou mengandung majas hiperbola karena kata “GROOT" 'Besar' memberikan kesan yang berlebihan. Ketika calon konsumen membaca iklan tersebut, Prof. Samiou berharap calon konsumennya akan memberikan persepsi bahwa jasa yang ditawarkan Prof. Samiou dapat dipercaya dan menjanjikan karena ia merupakan orang yang berpendidikan tinggi serta unggul.

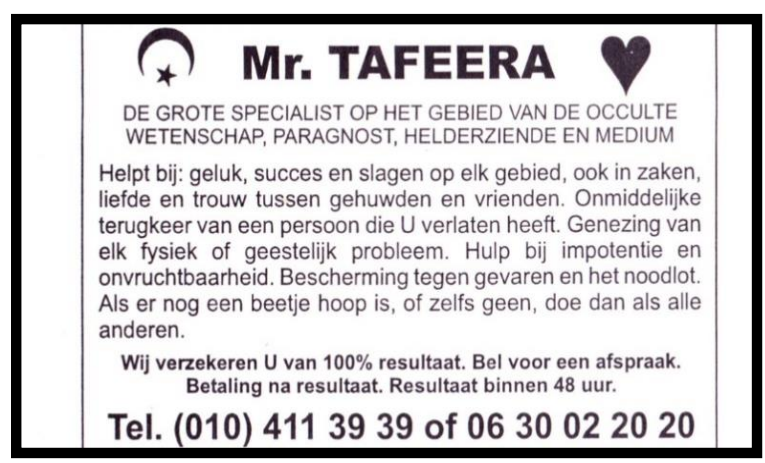

Gambar 9. Iklan Penyedia Jasa Klenik oleh Mr. Tafeera

Pada iklan penyedia jasa klenik di atas, terdapat slogan yang berbunyi "Wij verzekeren U van $100 \%$ resultaat. Bel voor een afspraak. Betaling na resultaat. Resultaat binnen 48 uur." 'Kami menjamin hasil $100 \%$. Hubungi untuk membuat janji. Pembayaran setelah hasil. Hasil dalam kurun waktu 48 jam.’. Kalimat slogan tersebut memiliki lokusi yang sama dengan ilokusinya karena kata yang disajikan dalam slogan mengandung makna tersurat. Tindak tutur ilokusi pada ujaran tersebut bermaksud untuk memberi jaminan kepada calon konsumen yang akan menggunakan jasa yang ditawarkan oleh penyedia jasa klenik. Pada umumnya semua orang membutuhkan jaminan agar tidak merasa rugi apabila terjadi kegagalan. Fungsi pemberian jaminan kepada calon konsumen yaitu guna membuat calon konsumen percaya dengan jasa yang ditawarkan dan apabila tidak mendapatkan hasil yang memuaskan maka calon konsumen tersebut dapat meminta pertanggungjawaban kepada si penyedia jasa klenik. Hal tersebut tentunya akan menarik perhatian calon konsumen yang sedang memiliki masalah untuk mendapat solusi dari penyedia jasa klenik. Jadi berdasarkan maksudnya, dapat dikatakan bahwa kalimat slogan pada iklan di atas merupakan tindak tutur komisif karena penyedia jasa klenik memberikan jaminan kepada calon konsumennya.

Pemilihan nama diri yang dipilih oleh Tafeera adalah Mr. Tafeera. Kata $M r$. merupakan kata sapaan dalam bahasa Inggris. Penggunaan kata sapaan tersebut 
karena terdengar lebih berkelas (Manurung, 2009). Meskipun sebenarnya di Belanda sendiri terdapat kata sapaan berupa Meneer, tetapi kata $M r$. merupakan kata yang berasal dari bahasa Inggris di mana bahasa tersebut lebih universal dibandingkan bahasa Belanda. Kata yang terletak di bawah nama Mr. Tafeera, "DE GROTE SPECIALIST OP HET GEBIED VAN DE OCCULTE WETENSCHAP, PARAGNOST, HELDERZIENDE EN MEDIUM' 'Spesialis besar dalam ilmu gaib, peramal, dan perantara' berfungsi untuk memberikan informasi mengenai dirinya. Kalimat " $D E$ GROTE SPECIALIST' 'Spesialis besar' mengandung majas hiperbola karena menimbulkan kesan yang melebih-lebihkan. Hal ini membuat seolah Mr. Tafeera benarbenar ahli dalam bidang yang telah disebutkan. Dapat disimpulkan cara yang digunakan Mr. Tafeera untuk mempromosikan dirinya yaitu dengan cara meggunakan kata sapaan $M r$ dan menunjukkan keunggulan dirinya melalui kalimat "DE GROTE SPECIALIST" 'Spesialis hebat'.

\section{SIMPULAN}

Berdasarkan hasil paparan di atas, dapat disimpulkan bahwa tindak tutur ilokusi yang banyak ditemukan pada slogan dalam iklan penyedia jasa klenik yang diteliti yaitu tindak tutur direktif yang berjumlah 3 kalimat dan tindak tutur komisif yang berjumlah 4 kalimat. Hasil penelitian memperlihatkan kecenderungan penggunaan bentuk tindak tutur direktif dan komisif bertujuan untuk memberi peringatan dan perintah, serta memberikan jaminan kepada calon konsumen. Penggunaan tindak tutur direktif lebih sedikit dibandingkan dengan tindak tutur komisif karena penyedia jasa klenik paham pentingnya pemberian jaminan kepada calon konsumen guna memenuhi harapan pengguna jasa tersebut. Dari 4 iklan yang telah diteliti terdapat 2 iklan yang kalimat slogannya memiliki tindak tutur lokusi yang sama dengan ilokusinya. Hal tersebut merupakan upaya yang dilakukan penyedia jasa klenik untuk mempromosikan dirinya, ia ingin calon konsumen langsung paham dengan pesan yang ia sampaikan tanpa harus mencaritahu makna dibalik pesan tersebut. Dari iklan yang sudah diteliti juga ditemukan adanya penggunaan majas hiperbola pada beberapa iklan penyedia jasa klenik.

Hasil penelitian juga memperlihatkan kata sapaan atau gelar selalu menyertai nama diri para penyedia jasa klenik. Kata sapaan yang digunakan merupakan kata sapaan dalam bahasa Inggris dan bahasa Belanda. Penggunaan nama diri yang diikuti dengan kata sapaan atau gelar merupakan sebuah cara yang digunakan penyedia jasa klenik untuk meyakinkan calon konsumen 
bahwa masalah yang mereka miliki akan terselesaikan di tangan yang ahli dalam bidang tersebut. Pada penelitian ini, peneliti masih menggunakan kata 'diduga' untuk penyedia jasa klenik allochtonen, diharapkan peneliti lain dapat membuktikan nama diri yang tidak lazim di kebiasaan penamaan orang Belanda terbukti allochtonen atau tidak. Penelitian ini juga menemukan terdapat majas hiperbola dalam kalimat slogan pada beberapa iklan penyedia jasa klenik. Oleh karena itu disarankan peneliti lain untuk menggali lebih dalam mengenai penggunaan majas hiperbola dalam kalimat slogan pada iklan penyedia jasa klenik.

\section{DAFTAR PUSTAKA}

Alex. (2019, November). Irritant: Nederlanders die Engels Spreken. https://www.taalvakman.nl/post/2019/1 1/16/irritant-nederlanders-die-engelsspreken

Baker, A.E., Don, J, dan Hengeveld, K. (2013). Taal en Taalwetenschap. Edisi ke-2. Amsterdam: Athenaeum Uitgeverij.

Danesi, Marcell, dan Paul Peron. (1999). Analyzing Cultures: An Introduction \& Handbook. Bloomington/Indianapolis: Indiana University Press.

Handayani, D. A. (2018). "Hiperbola dan Hiperrealitas Media: Analisis Judul Berita Hiperbola di Situs Berita Online", dalam: Dialektika: Jurnal
Bahasa, Sastra, dan Pendidikan Bahasa dan Sastra Indonesia, 5(2), 120-134.

Hidayat. (2010). Istilah Khas dalam Wacana Iklan Perdukunan. Semarang: Magister Linguistik Pps UNDIP.

Houtkoop \& Koole. (2000). Taal in Actie. Amsterdam: Uitgeverij Coutinho.

Indrawan, Iwan. (2015). Konotasi NamaNama Diri: Sebuah Studi tentang Sikap Bahasa Dosen Dilihat dari Persepsi Mereka tentang Tingkat Kecerdasan Mahasiswa Berdasarkan Nama-Nama Mereka. Denpasar: Institut Hindu Dharma Negeri.

Kasali, Renald. (1995). Manajemen Periklanan: Konsep dan Aplikasinya di Indonesia. Jakarta: Pustaka Utama Grafiti.

KBBI. (2019). Kamus Besar Bahasa Indonesia $\quad(K B B I)$. Versi 2.8. https://kbbi.web.id/klenik

KBBI. (2019). Kamus Besar Bahasa Indonesia $\quad(K B B I)$. Versi 2.8. https://kbbi.web.id/slogan

Khoirunnisa, E. M. (2018). "Analisis Tuturan Performatif dalam Pidato Shinzo Abe" dalam Jurnal Sasindo UNPAM, Pamulang.

Kumalasari, Diah. (2015). Tindak Tutur dalam Rayuan Gombal Bahasa Belanda "Openingszinnen" pada Laman www.leukerspreuk.nl: Sebuah Kajian 
Pragmatik. Depok: Universitas Indonesia.

Kushartanti. (2005). "Pragmatik", dalam: Kushartanti et al. Hlm. 106-110.

Kushartanti, U. Yuwono, dan M.R.M.T. Lauder (ed.). (2005). Pesona Bahasa. Jakarta: Gramedia.

Lestari, S. (2013). Kajian Ragam Bahasa Slogan Pada Papan Reklame Di Kota Medan (Kajian Sosiolinguistik). Medan: Basastra.

Martutik, M. (2013). Isi Pesan Persuasif dalam Advertorial Media Massa. Bahasa dan Seni: Jurnal Bahasa, Sastra, Seni, dan Pengajarannya.

Paragnost Eddie \& Consulten. (2015). Medium Roos. Steenwijk: Eddie.eu. https://www.paragnosteddie.n1/consulent/paragnost-elisa-lis/

Paragnost Eddie \& Consulten. (2016). Paragnost Elisa-Lis. Steenwijk: Eddie.eu. $\quad$ https://www.paragnosteddie.nl/consulent/paragnost-elisa-lis/

Prihaditama. (2016). Fenomena Klenik dalam Politik. Yogyakarta: Universitas Negeri Yogyakarta.

Religious and Alternative Healing Research Platform (RAHRP). (2015). Flyers of healers in the Netherlands on healing and problemsolving. Amsterdam: Marteens Institut. http://www.rahrp.org/cms/visuals/flyers -on-healing-and-problemsolving/
Rohmadi, Muhammad. (2004). Pragmatik:

Teori dan Analisis. Yogyakarta: Lingkar Media.

Sopian. (2016). Public Relations Writing: Konsep, Teori, Praktik. Jakarta: PT Grasindo.

Van Dale. (2020). Van Dale Online. https://www.vandale.nl/gratiswoordenboek/nederlands/betekenis/mag netiseur\#.XwK VCgzbIU

Veriyani, Eti. (2011). Analisis Wacana Persuasif dalam Iklan Barang Elektronik pada Surat Kabar Suara Merdeka. Purwokerto: Universitas Muhammadiyah Purwokerto. 